\title{
Prevalence of Neck Pain and Its Different Associated Factors Among Undergraduate Students of Sargodha Medical College
}

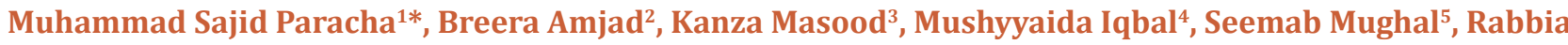 \\ Naseer $^{6}$, Hafiz Muhammad Junaid Hassan ${ }^{7}$ and Asif Ali Butt ${ }^{8}$
}

${ }^{1}$ Assistant Professor, Isra University, Islamabad Campus

${ }^{2}$ Senior Lecturer, Riphah International University, Faisalabad

${ }^{3}$ Lecturer, University of Lahore, Sargodha Campus

${ }^{4} \mathrm{HOD}$, Sargodha Institute of Health Sciences

${ }^{5}$ Lecturer, University of Balochistan

${ }^{6}$ Lecturer, University of Balochistan

${ }^{7} \mathrm{CEO}$, Healthcare Physiotherapy sports, Spine Rehabilitation Center, Faisalabad

${ }^{8}$ Associate Professor, Riphah International University, Faisalabad

Submission: September 11, 2019; Published: September 24, 2019

*Corresponding author: Muhammad Sajid Paracha, Assistant Professor, Isra University, Islamabad Campus

\begin{abstract}
Aim of Study: To find the prevalence of neck pain variation among undergraduate medical students of different academic years also exploring association of different study posture, study hours and different mode of study with neck pain among undergraduate medical students.

Study Design: Observational Study

Methodology: The study was conducted in Sargodha Medical College. 500 undergraduate students fulfilling inclusion and exclusion criteria using self-created questionnaire (approved by University of Sargodha) to observe prevalence of self-reported neck pain symptoms \& disability.

Results: This study concluded that out of 200 undergraduate medical students of Sargodha medical college $38 \%$ had neck pain. Out of these students $64.5 \%$ had acute neck pain while $35.5 \%$ had chronic neck pain, more prevalent in female students than in males having a percentage of $67 \%$ in females and $33 \%$ in males. Neck pain is more common among senior most (final year) students i.e. 39.5\% due to increased study hours. A remarkable but unexplained finding was $21.1 \%$ incidence among 1st year students. A gradual rise in percentage of students suffering from neck pain is seen from 2nd year to final year students. Maximum time one can study without pain by $36.8 \%$ students was $2-4$ hours. $26.3 \%$ could study for 4-6 hours, in 25\% neck pain starts even with less than 2 hours of study while only $11.8 \%$ students are capable of studying for more than 6 hours after which they also start experiencing pain. Moreover, studying posture $72.4 \%$ reported that they study in lying position while $17.1 \%$ used to assume table / chair sitting and $10.5 \%$ study in floor sitting position. Higher percentage among subjects who assume lying positioning suffered from neck pain. Finally, $81.6 \%$ of target population having neck pain used books while rest $18.4 \%$ used other devices like computer/ laptop or tablet most of the times for study.
\end{abstract}

Conclusion: All the findings of this study strongly supports the hypothesis that neck pain is common in undergraduate medical students and showed association with posture of study, academic year, continuous study hours, mode of study.

Keywords: Fluctuating pain; Cervical spine; Thoracic kyphosis; Ergonomics; Psychological risk factors; Ligamentum flavum; Smoking; Sedentary

\section{Introduction}

Neck pain is a chronic episodic condition characterized by persistent, non-transient or fluctuating pain [1]. It is a complaint by young adults having 14-71\% incidence sometimes in their lives [2]. Neck pain indicates potential damage to structures of cervical spine. Cervical spine is lordotic (convex anteriorly) curvature $\mathrm{c}$ having seven vertebrae which are smaller in size than rest of the vertebral column. First\& second vertebrae (atlas \& axis) are atypical making atlanto-occipital \& atlanto-axial joints. 
Movements occur at cervical spine are flexion, extension, lateral flexion and rotation. The ranges of these movements vary among upper and lower cervical region. Most of flexion and rotational movements are permitted in this region as compared to rest of the spine.

When we bend the neck, tensile load is formed on one side and a compression load on other side. The excessive load on neck will leads to disc degeneration in future. It commonly occurs at C5-C6 vertebra and C6-C7 vertebrae [3]. C-spine becomes s-shaped with upper segment in flexion and lower segment in extension. Forward head posture results in increased thoracic kyphosis, round shoulders and protracted scapulae, and characterized by increased flexion of lower cervical segment and increased extension of upper cervical segment. Symptoms of faulty posture includes;

a. Fatigue to scapular retractors.

b. Impingement of nerves in cervical region.

c. Tight trapezius muscle leads to the headache.

d. Chances of disc lesion are increased due to faulty flexed posture of neck

e. Degenerative changes in cervical region by age resulting in decreased intervertebral foramina space and impinging the nerve roots

f. Extreme stiffness and stress in ligamentum flavum in lower cervical region and to anterior longitudinal ligament in upper cervical region [4].

Neck pain may be caused by a number of pathologies of cervical spine. A number of risk factors are responsible for origin of neck pain. These factors can be categorized as individual, physical \& psychological risk factors [5].

Individual risk factors include gender, age, lifestyle, and low physical fitness level, high demands of study, poor ergonomics, abnormal muscle strength \& endurance. Smoking\& sedentary lifestyle may also be included. Physical risk factors include posture \& duration of study. In category of psychosocial risk factors, stresses, coping ability\& social support are included. One important risk factor for neck pain is gender [6]. Women are more prone to develop neck pain than men \& this risk increases with age [7-9]. Age is also an important factor. Incidence of neck pain or neck shoulder trouble (NST) gets higher with increasing age. Hence older adults are more prone to neck pain than younger ones. Higher level of education can also cause neck pain as students spend more time in study [10]. Posture is of great importance in this aspect. A sound subject can have neck pain if he/she continues to flex neck for even more than 15 minutes [11]. Hence people who adopt a flexed neck posture are more prone to develop neck pain [12].

\section{Materials and Methods}

An observational study was conducted in Sargodha Medical College among 200 undergraduate students. Falling in age limit of 18-25 years. The study time frame was March 2015 - August 2015. It was an observational study, conducted via survey. Selfstructured questionnaires were distributed to 200 randomly selected undergraduate medical students of Sargodha medical college. $100 \%$ response was obtained. A questionnaire was designed according to demands of study. Data was collected by distributing printed self-structured questionnaires containing close ended questions approved by university of Sargodha among randomly undergraduate medical students fulfilling the inclusion criteria. The questionnaire consisted of 3 main parts. First part consisted of biodata of the participant asking name, age, gender, year of study in institute. Second part comprised of 5 questions regarding onset, duration, intensity of pain as well as posture and mode of study chooses for most of the times. The data was compiled by using Microsoft excel in form of table, figures and graphs.

\section{Results}

This study concluded that out of 200 undergraduate medical students of Sargodha medical college 38\% had neck pain. Out of these students $64.5 \%$ had acute neck pain while $35.5 \%$ had chronic neck pain, more prevalent in female students than in males having a percentage of $67 \%$ in females and $33 \%$ in males. Neck pain is more common among senior most (final year) students i.e. $39.5 \%$ due to increased study hours. A remarkable but unexplained finding was $21.1 \%$ incidence among 1 st year students. A gradual rise in percentage of students suffering from neck pain is seen from 2 nd year to final year students. Maximum time one can study without pain by $36.8 \%$ students was $2-4$ hours. $26.3 \%$ could study for $4-6$ hours, in $25 \%$ neck pain starts even with less than 2 hours of study while only $11.8 \%$ students are capable of studying for more than 6 hours after which they also start experiencing pain. Moreover, studying posture $72.4 \%$ reported that they study in lying position while $17.1 \%$ used to assume table / chair sitting and $10.5 \%$ study in floor sitting position. Higher percentage among subjects who assume lying positioning suffered from neck pain. Finally,81.6\% of target population having neck pain used books while rest $18.4 \%$ used other devices like computer/laptop or tablet most of the times for study (Table 1-3).

Table 1: Pain trends with gender.

\begin{tabular}{|c|c|c|c|}
\hline \multicolumn{2}{|c|}{} & Frequency & Percent \\
\hline \multirow{3}{*}{ Valid } & Female & 51 & 67.1 \\
\cline { 2 - 4 } & Male & 25 & 32.9 \\
\cline { 2 - 4 } & Total & 76 & 100 \\
\hline
\end{tabular}


Journal of Yoga and Physiotherapy

Table 2: Statistics of pain variation among students of different academic years.

\begin{tabular}{|c|c|c|c|}
\hline \multicolumn{2}{|c|}{} & Frequency & Percent \\
\hline \multirow{4}{*}{ Valid } & 1st year & 16 & 21.1 \\
\cline { 2 - 4 } & 2nd year & 8 & 10.5 \\
\cline { 2 - 4 } & 3rd year & 10 & 13.2 \\
\cline { 2 - 4 } & 4th year & 12 & 15.8 \\
\cline { 2 - 4 } & final year & 30 & 39.5 \\
\cline { 2 - 4 } & Total & 76 & 100 \\
\hline
\end{tabular}

Table 3: Statistics of posture of study.

\begin{tabular}{|c|c|c|c|}
\hline \multicolumn{2}{|c|}{} & Frequency & Percent \\
\hline \multirow{3}{*}{ Valid } & chair sitting & 13 & 17.1 \\
\cline { 2 - 4 } & Lying & 55 & 72.4 \\
\cline { 2 - 4 } & floor sitting & 8 & 10.5 \\
\cline { 2 - 4 } & Total & 76 & 100 \\
\hline
\end{tabular}

\section{Discussions}

This study indicates that the prevalence of neck pain among undergraduate medical students was $38 \%$. Of these students $64.5 \%$ had acute while $34.5 \%$ had chronic neck pain. A no of factors has been studied under this topic. This study showed that it is more prevalent in female students than in males having a percentage of $67 \%$ in females and $33 \%$ in males supporting previous researches that one important risk factor for neck pain is gender [13]. Women are more prone to develop neck pain than men \& this risk gets increased with age $[9,11,14]$.

Age related variations were similar to previous researches with $46.1 \%$ in $21-23$ years age group, $27.6 \%$ in $18-20$ years and $26.3 \%$ in $24-25$ years age group. Pain intensity varied among students as $48.7 \%$ had moderate pain, $44.7 \%$ had mild and only $6.6 \%$ had severe pain. Gender and age specific variations are seen because female compared to males are less capable to withstand stresses of study and with the passage of chronological time, continuous bad posture can lead to structural and functional musculoskeletal impairments producing pain symptoms.

Year of study is also an important factor as neck pain is more common among final year students i.e. $39.5 \%$ due to increased study hours. Remarkable but unexplained finding was $21.1 \%$ incidence among 1st year students. A gradual rise in percentage of students suffering from neck pain is seen from 2 nd year to final year students. Explanation probably lies in progressively increased study hours or tough study schedule.

Posture has great importance in all musculoskeletal disorders. Researcher also focused on this aspect asking subjects about most commonly adapted posture while studying. $72.4 \%$ reported that they study in lying position while $17.1 \%$ used to assume table / chair sitting and $10.5 \%$ study in floor sitting position. Higher percentage among subjects who assume lying position is due continuous flexion of cervical spine for studying. Previous study concluded that posture has great importance.
A sound subject can have neck pain if he/she uses continuously flexed neck for even more than 15 minutes [15]. Hence people who assume a flexed neck posture are more inclined to develop neck pain [16]. Maximum time one can study without pain by $36.8 \%$ students was $2-4$ hours. This is the maximum time of study after which majority of students start experiencing pain symptoms. $26.3 \%$ could study for 4-6 hours, in $25 \%$ neck pain starts even with less than 2 hours of study while only $11.8 \%$ students are capable of studying for more than 6 hours after which they also start experiencing pain. These results show that whenever a subject complains about neck pain, his /her duration of continuous study is affected a lot and they study symptom free for less duration as compared to before. One of previous studies reported that continuous study hours also impose stresses while pauses \& breaks during study or work as well as exercises have shown great effect on neck pain [17].

Mode of study is also an important factor. It involves sort of material used for study purpose i.e. books / laptops or computers etc.as these different modes have different postures assumed by reader. Students using books placed below eye level tends to have a flexed posture so with tablet users while computer or laptop screen placed at eye level leads to neutral position of neck for study. Researcher found that $81.6 \%$ of target population having neck pain used books while rest $18.4 \%$ used other devices like computer/laptop or tablet most of the times for study. Cause of maximum incidence among book readers probably lies in the fact that they keep their necks flexed during most of their study hours leading to production of symptoms. In this study $61.8 \%$ students reported that they experience headache along with neck pain. Rest $38.2 \%$ students did not have such complaint. Sleep disturbance is also seen in subjects with neck pain caused by musculoskeletal discomfort. In this study $50 \%$ of the target population reported that they have sleep disturbance while rest 50\% didn't have such complaint. The factor behind this finding might be associated with poor sleeping posture or 
continuous severe pain in neck region. All the findings of this study strongly support the hypothesis that neck pain is common in undergraduate medical students. It showed strong association with posture and mode of study.

\section{Conclusion}

This study concludes that out of 200 undergraduate medical students of Sargodha Medical College between ages 18-25, 38\% had neck pain. Of these students $64.5 \%$ had acute while $35.5 \%$ had chronic neck pain. Different risk factors are associated with this incidence and persistence including age, gender, academic year, continuous study hours, mode of study, faulty posture of study.

\section{References}

1. Deshpande PB (2006) Improve health and reduce healthcare costs from pranayama with six sigma; in association with Louisville Pranayama Group, Louisville, Kentucky, Reflections 5.

2. Muscle Activity during Yoga Breathing Exercise Compared to Abdominal Crunches.

3. Deshmukh S, Bedekar N (2017) Effect of Kapalbhati pranayama on core strength in overweight individuals. International Journal of Yoga, Physiotherapy and Physical Education 2(3): 50-51.

4. Coulter D (2010) Anatomy of Hatha yoga. Motilal banarasidass, New Delhi, India

5. Kulkarni G, Bedekar N (2014) An Experimental Study of Selected Yoga Poses on Young Adult Female Population Reporting Primary Dysmenorrhoea. VIMS Health Sci Journal 1(3): 125-129.
6. Prabhu S, Nagrale S, Shyam A, Sancheti P (2019) Effect of yogasanas on menstrual cramps in young adult females with primary dysmenorrhea. International Journal of Physiotherapy and Research IJPR 7(4): 31293134.

7. Rathore M, Trivedi S, Abraham J, Sinha MB (2017) Anatomical Correlation of Core Muscle Activation in Different Yogic Postures. Int J Yoga 10(2): 59-66.

8. Ni M, Mooney K, Harriell K, Balachandran A, Signorile J (2014) Core muscle function during specific yoga poses. Complement Ther Med 22(2): 235-43.

9. Ferreira M, Mariana Saavedra M, Santos P (2018) Yoga therapy in pregnancy. Journal of Yoga and Physiotherapy 4(1).

10. Cervone M, Neville C (2018) Mula Bandha and Raising Awareness about Pelvic Floor Dysfunction Journal of Yoga and Physiotherapy 4(5).

11. Sweta KM, Godbole A, Awasthi HH, Pandey U (2018) Effect of Mula Bandha Yoga in Mild Grade Pelvic Organ Prolapse: A Randomized Controlled Trial. Int J Yoga 11(2): 116-121.

12. Jakhotia KA, Shimpi AP, Rairikar SA, Mhendale P, Hatekar R, et al. (2015) Surya namaskar: An equivalent approach towards management of physical fitness in obese females. Int J Yoga 8(1): 27-36.

13. Deshmukh A, Chincholkar S, Sutar A, Ghodey S (2018) A comparative study between Pilates and Surya namaskar on flexibility in women having sedentary lifestyle using sit and reach test and shoulder and wrist test. International Journal of Yoga, Physiotherapy and Physical Education 3(2): 190-195.

14. Muruguvalavan V, Jayanthi V (2019) Effect of surya namaskar on body mass index, systolic and diastolic blood pressure among obese working women. International Journal of Yogic, Human Movement and Sports Sciences 4(1): 976-977.

\section{Your next submission with Juniper Publishers} will reach you the below assets

- Quality Editorial service

- Swift Peer Review

- Reprints availability

- E-prints Service

- Manuscript Podcast for convenient understanding

- Global attainment for your research

- Manuscript accessibility in different formats

( Pdf, E-pub, Full Text, Audio)

- Unceasing customer service

Track the below URL for one-step submission

https://juniperpublishers.com/online-submission.php 